\title{
Schrödinger's Katniss: A Diffractive Reading of Quantum Entanglement and The Hunger Games
}

\author{
Rosie Clarke \\ University of Queensland
}

Abstract: Can a close reading of The Hunger Games shed new light on Schrödinger's thought experiment? When read diffractively, both Suzanne Collins' The Hunger Games series and Erwin Schrödinger's Cat Paradox privilege indeterminacy and (im)probability in ways that affirm posthuman understandings of identity. Juxtaposing the 'real' dead-alive cat featured in Collins' young adult fiction series alongside Schrödinger's hypothetical one provides an opportunity to understand quantum ontology differently. This diffractive reading explores Karen Barad's meditation on quantum mechanics as an emerging branch of literary criticism. A growing body of criticism undertakes posthumanist and queer readings of young adult fiction to explore central themes, including life/death, human/animal, and future/past. As an example of diffractive reading practice, this analysis of The Hunger Games is an iterative reworking of Barad's framework that ultimately positions mourning as an (intra-)act of constructive remembrance. Mourning in this sense parallels the diffractive reading process as productive and affirming, rather than negative and critically consumed with absence.

\section{The Haunting Significance of 'Buttercup the Cat'}

In the first few pages of Suzanne Collins's The Hunger Games, Katniss Everdeen reveals she almost killed a cat. When her sister, Primrose, brings the cat home, Katniss says she does not want "another mouth to feed" (Collins, The Hunger Games 3) and tries to drown him in a bucket. However, Prim cries, Katniss stops, and the cat survives. Later, District 12 is bombed and 'Buttercup the cat' is presumed to have died alongside District 12's entire population. However, Katniss returns to survey the damage and is shocked to find the cat alive. Later still, near the end of the series, Katniss returns to the ruins of their hometown to mourn her sister alone and is once again shocked to encounter Buttercup, this time after having left him for dead in a radioactive warzone. In each instance, it is impossible for Katniss to know whether Buttercup is dead or alive until she finds him.

Also featuring a dead-alive cat, Schrödinger's thought experiment is a well-known meditation on quantum entanglement that feminist theorist Karen Barad uses to explore ontological indeterminacy and their concept of intra-action. Erwin Schrödinger imagined a cat, sealed in a box, rigged with a radioactive device that has a $50 \%$ chance of killing the cat. Until the box is opened, there is no way to know whether the device has activated or whether the cat is alive; the life/death binary is effectively and paradoxically blurred. This thought experiment is an epistemological one that suggests the observer outside the sealed box cannot know whether the cat is alive or dead. According to Barad, it is a common misconception that the cat is both dead and alive at the same time. They find that there is more to it: 
I argue that the correct way to understand what this superposition (or "blurring") stands for is to understand that the cat's fate is entangled with the radioactive source-and not merely epistemically, as Schrödinger and others suggest, but ontically; that is, the cat and the atom do not have separately determinate states of existence, and, indeed, there is no determinately bounded and propertied entity that we normally identify with the word "cat," independently of some measurement that resolves the indeterminacy and specifies the appropriate referents for the concepts of "cat" and "life state". (Barad, "Living" 170)

Here, the way in which concepts and entities like 'cat' or 'life state' are determined is what determines them: "Measurements are world-making: matter and meaning do not pre-exist, but rather are co-constituted via measurement intra-actions" (Barad, "What is" 6). To illustrate their point, Barad explains that electrons are alternately particles and waves when measured in two different ways. If the way something is measured changes it, they argue, how can we say anything is finite? Asking whether apparatus used to measure the 'aliveness' of a 'cat' would work for different 'life states' in the same precariously lethal scenario, they further argue that human judgement as a measure is also intra-active because humans "must also be understood as [...] produced through the intra-action of multiple material-discursive apparatuses of bodily production" (Barad, "Living" 172).

Accordingly, Schrödinger's cat and Katniss's cat are 'alive' or 'dead' because of many material-discursive factors that produce the moment in which the 'possible killing' by device or war or bucket occurs (or not) and also produces the moment in which Schrödinger and Katniss determine that their respective cats are alive or dead. "It is through specific measurement intra-actions that the boundaries and properties of the 'measured object' and 'measuring instrument' become determinate, and that particular embodied concepts (like "life") become meaningful" (Barad, "Living" 171). This intra-activity is called entanglement in quantum mechanics; Schrödinger's cat is entangled with the atom device and Buttercup is entangled with Katniss. Furthermore, the intra-active phenomenon "includes the entangled and enfolded sets of apparatuses of bodily production of all the beings and devices relevant to this specific example" (Barad, "Living" 171). Katniss is, perhaps unintentionally, correct when she bemoans the persistent presence of Buttercup in her life: "We're about as much company for each other as dirt" (Collins, Mockingjay 133). While this reading focuses on the entanglement between Katniss and Buttercup (and, later, Prim) portrayed in The Hunger Games narrative; more broadly speaking, all matter is entangled, not just cats and atomic devices and young adult fiction protagonists but all particles that make up reality. This close reading develops its own diffractive methodology in an attempt not just to read The Hunger Games differently through Barad's account of quantum mechanics, but to read Barad's account of quantum mechanics differently through The Hunger Games. ${ }^{[1]}$

In a Baradian context, Buttercup's importance to The Hunger Games narrative is comically large. While this effect risks accusations of superficiality, producing jokes by reading different knowledges and texts together exemplifies how diffractive modes create space for new perspectives. For example, only by elevating the status of a minor character like 'Buttercup' to a laughable extent does this diffractive reading come to consider mourning as ontological superposition, or an intra-active experience of (non)identity. In the same way Barad suggests that Schrödinger's cat's fate is entangled with the atom device, Buttercup's fate is entangled with Katniss. Funnily enough, Katniss makes this observation herself in the third book when she admits to the reader: "I am Buttercup" (Collins, Mockingjay 113). While such substantial focus on a minor character like Buttercup may seem absurd, Donna Haraway describes how readings "produce jokes" when a diffractive methodology is undertaken as part of an affirmative rather than critical close reading (Haraway, "Conversations" 149). ${ }^{[2]}$ She says: 
The classic example that Samuel Delaney used was the phrase 'her world exploded'. In ordinary literature that generally means a psychological crisis. In a science fiction novel, it probably means the world exploded. (Laughing) Right? Probably not a psychological crisis at all, and that's an example of a diffractive reading; the two ways of reading make you laugh when they are juxtaposed, and then you read each differently because you read the other. (Haraway, "Conversations" 149; original emphasis) ${ }^{[3]}$

While the juxtaposition is comical, reading The Hunger Games through Karen Barad's work on quantum entanglement iteratively reworks their take on Schrödinger's thought experiment to create space for different configurations of meaning. ${ }^{[4]}$

Jacques Derrida makes a similar move in The Animal That Therefore I Am when he juxtaposes a surprise cat encounter with a brief reading of Lewis Carroll's Alice in Wonderland. The juxtaposition forms a small part of his argument but highlights his central question: how can humans be so certain of their ability to distinguish response that they insist animals cannot respond at all? Discussing an encounter between the titular Alice and a speaking Cheshire Cat, Derrida asks whether the notion of a talking cat is any more absurd than believing it is possible for humans to "discern and decide between a human yes and no" (The Animal 9). After all, in Carroll's Through the Looking Glass, Alice reasons that kittens do not follow any grammatical law and therefore cannot be understood, "the kitten only purred: and it was impossible to guess whether it meant 'yes' or 'no'" (qtd. in Derrida, The Animal 8). Moreover, Derrida says that elsewhere in the novel it is actually the talking cat who tells Alice "they are unable to agree on the sense of the words, on what a word means, and . . what the term word could ever mean" (9). So, rather than ask whether the cat he encounters in his bathroom responds to him, Derrida deconstructs the encounter to question his capacity for distinguishing response in the first place.

Donna Haraway agrees this question is key but regrets that Derrida never moves beyond the Western canon to configure answers. Instead, The Animal That Therefore I Am deconstructs the human/animal binary at play in Derrida's cat encounter by tracing a history of 'the animal' in philosophy from Plato, Lévinas, and Descartes, through to Heidegger. By taking this approach, Haraway claims that Derrida "missed" an opportunity for "otherworlding" because he "failed" to "become curious about what the cat might actually be doing . . . in looking back at him that morning" ("Encounters with Companion Species" 103-104): "Why did Derrida not ask, even in principle, if a Gregory Bateson or Jane Goodall or Marc Bekoff or Barbara Smuts or many others had met the gaze of living, diverse animals, and in response undid and redid themselves and their sciences?" (104). In her reading of Derrida, Haraway makes it clear that exploring human-animal ontology and relationality is a "radical practice" that requires the development of diffractive methodologies (107). [5] While she does not consider his methodology here particularly radical, Derrida's short 'reading together' of Alice in Wonderland and his bathroom cat encounter could be considered a diffractive reading in the sense that he "reads each differently because [he] read the other" (Haraway, "Conversations" 149). Describing his animal encounter, Derrida posits that the cat is real, not metaphorical, but something that has "the point of view of the absolute other" (The Animal 11).

I must immediately make it clear, the cat I am talking about is a real cat, truly, believe me, a little cat. It isn't the figure of a cat. It doesn't silently enter the bedroom as an allegory for all the cats on the earth, the felines that traverse our myths and religions, literature and fables. There are so many of them." (Derrida, The Animal 6)

Derrida makes this point seriously about encountering 'really a little cat' but light-heartedly borrows the line from Carroll's Through the Looking Glass. ${ }^{[6]}$ The reference could be overlooked as insignificant, perhaps juvenile, in the context of his lengthy discussion about the epistemological and ontological state of 'cats' across canonical Western philosophy. Yet, its humour is significant given Haraway's assertion that diffractive readings "produce 
jokes" ("Conversations" 149). When Derrida wryly notes that readers are free to "understand or receive" his emphasis on "a quote from chapter 11 of Through the Looking Glass", he juxtaposes how he reads literature with how he reads, or responds to, his cat (The Animal 7). Moreover, his joke implies that while he views the cat as existing outside of text, as other, Derrida himself believes he can only view the cat through text, which is to say through the trace of every cat figure in literature and otherwise that he has also encountered. All this positions Derrida's style of reading as a kind of steppingstone towards the diffractive reading process later developed by Haraway and then Barad. ${ }^{[7]}$

For Donna Haraway, it seems clear that Derrida's reading method is not diffractive enough. She argues that he could have reached more conclusions by "reading what people who study cats have to say" so that these "different reading skills" could "interrupt each other productively" ("Encounters with Companion Species" 106; Interview 149). Instead, "he got sidetracked by his textual canon of Western philosophy and literature" (Haraway, "Encounters with Companion Species" 103). Still, Haraway maintains: "For those readings, I and my people are permanently in his debt" (103). ${ }^{[8]}$ For Barad, this "indebtedness" takes on material significance as part of their interpretation of entanglement; they remark, "our debt to those who are already dead and those not yet born cannot be disentangled from who we are" ("Quantum Entanglements and Hauntological Relations" 265, 266). And in this sense, although more radical accounts of different human-animal relations have emerged since Derrida, each of these accounts may be read as an entangled "iterative reworking" of his account rather than a wholly

critical revision (Barad 265). [9] To this point, Barad describes their "readings of quantum physics" as "shot through with readings of . . . Derrida" ("What Flashes Up" 42). Derrida did not engage with quantum theory himself, but Barad's understanding of quantum physics is indebted to him. Clayton Crockett suggests that this reflects the paradoxical nature of quantum entanglement: "[Barad] argues that Derrida's philosophy offers a better way to understand this situation than many of the interpretations supplied by quantum physicists" (130). Barad reads Derrida differently as they read quantum mechanics differently; and they read them together to find that "words, concepts, phenomena are entangled in complex ways ... Our entangled intra-actions as large slow beings repeat in a different way the relations among subatomic particles" (Crockett 130). It is this notion of reading more differently, embracing iterative reworkings, that inspired the methodology of this close reading.

\section{The Entangled Relation That Therefore I Measure}

Karen Barad's diffractive methodology configures the space between their and Derrida's perspective on the human-animal relation. Derrida encounters the animal's otherness as an experience of some limit to human perception; he and the cat are separate, and that separateness causes him to self-reflect. Whereas Barad rejects the determinacy of any encounter between separate 'selves'. They infer that the encounter itself between animal and human creates 'human perception' along with the supposed entities of 'human' and 'animal', 'other' and 'self'. This suggests the Derrida-cat relation is, like all entanglements, "not about any difference but about which differences matter" (Barad, "Invertebrate Visions" 231). ${ }^{[10]}$ All reality is materially re-configured through entanglements, which are measured diffractively, for Barad. In terms of the Katniss-Buttercup relation in The Hunger Games then, Katniss echoes Barad's view of entanglement when she proclaims, "I am Buttercup" (Collins, Mockingjay 113). Katniss and Buttercup are not separate, reflective selves, but a paradoxical and mutually configured Katniss-Buttercup relation. Buttercup's fate is entangled with Katniss in the same way Schrödinger's cat's fate is entangled with the atom device, and perhaps Derrida is entangled with his 'little cat'. Furthermore, Katniss experiences her epiphany while flashing a beam of light around a dark room to tease Buttercup. In this 
encounter, she finds that she too feels teased by someone, her enemy President Snow. And this performative intra-action, where Katniss observes the cat as he responds to her flashlight, produces a series of revelations that transform Katniss.

As long as Buttercup feels he has the chance of catching the elusive light under his paws, he's bristling with aggression. (That's how l've been since I left the arena, with Peeta alive.) When the light goes out completely, Buttercup's temporarily distraught and confused, but he recovers and moves on to other things. (That's what would happen if Peeta died.) But the one thing that sends Buttercup into a tailspin is when I leave the light on but put it hopelessly out of his reach, high on the wall, beyond even his jumping skills. He paces below the wall, wails, and can't be comforted or distracted. He's useless until I shut the light off. (That's what Snow is trying to do to me now, only I don't know what form his game takes.) Maybe this realization on my part is all Snow needs ... And it's under the weight of this revelation that I truly begin to break. (Collins, Mockingjay 113)

During this encounter with Buttercup, Katniss constructs a view of her reality that "truly" pushes her to a psychological breaking point (113). Simultaneously, Buttercup's physical movements and emotions transform in response to Katniss's actions; he experiences "aggression", confusion, hopelessness (113). As the two characters 'play' this game, they construct a scene in which they become intelligible to one another. Katniss moves the light in response to the way Buttercup "moves", "paces", performs, and responds to her memories of the past and fears for the future (113). As Barad puts it, "There is no absolute boundary between here-now and there-then" (Barad, "Diffracting" 168). Their entanglement is transformative: it affects their behaviour and reconfigures their reality by producing spacetime through which they intra-act.

In conversation with Derridean trace, Barad makes the point that entanglements do not describe the "intertwining" of natural, stable identities or events, but create "relations of obligation [...] enfolded traces of othering" where "otherness is an entangled relation of difference" ("Quantum Entanglements and Hauntological Relations" 265). For Derrida, even a 'real' cat is textually constructed to the extent that it is perceived; in which case, Derrida's perception of a cat denotes the intertwining of an entity known as Jacques Derrida and an other entity known as 'a little cat'. In Derrida's view: "It is true that I identify it as a male or female cat. But even before that identification, it comes to me as this irreplaceable living being ..." and "nothing can ever rob me of the certainty that what we have here is an existence that refuses to be conceptualized" (Derrida, The Animal 9). In this context, Barad's critical intervention reworks Derrida's cat encounter into an entanglement that is mutually and ontologically constructive rather than textually constructed. As a form of 'measurement', in other words, perception is part of the material encounter and does something transformative; the cat's perceived 'otherness is an entangled relation of difference'. While Derrida wonders how the presence of the cat as other may call his human perception of reality into question, Barad suggests any perception of reality is part of an experience of reality that creates reality; so, in their 'encounter', 'Derrida' and the 'cat' as other create material and perceived reality by intra-acting. Likewise, the entangled relation of Katniss-Buttercup is Katniss and Buttercup. Tracing the 'identity' of one reconfigures or transforms the 'identity' of the other. Moreover, this disrupts any fixed notion of death because entangled relations are not separately embodied entities that live and die, but are continually "enfolded traces" that form and reform reality (265).

Another example of spacetime entanglement occurs early in the first novel, when Katniss recalls her father saying, "As long as you can find yourself, you'll never starve" (Collins, The Hunger Games 49). He is "joking" (49) about Katniss being named after an edible katniss plant. However, Katniss views the joke as prophetic after her father dies. Only when she remembers his joke does she find enough edible katniss plants to keep herself and her starving family alive. By contrast, at the end of the series, Katniss struggles to feel alive: she has nightmares about dying, being buried, and is surrounded by mass graves. She only "come[s] back to life" once Buttercup 
finds her and she feeds him (Collins, Mockingjay 269). ${ }^{[11]}$ Considering Katniss's understanding that she is Buttercup, her father's joke foreshadows the blurring of identity inherent to entanglement; the 'you' he refers to may just as well apply to Buttercup. The title of The Hunger Games series may even refer to the mutually configured, entangled reality where Katniss and Buttercup continually perform intra-active games to find one another so they 'never starve'. When they reunite, Katniss describes their physical responses: "a new sound, part crying, part singing, comes out of my body, giving voice to my despair. Buttercup begins to wail as well" (Collins, Mockingjay 269). ${ }^{[12]}$ Their fates are entangled as their identity blurs together in their process of staying alive. In other words, Katniss and Buttercup 'measure' each other every time they reunite and, in doing so, uphold the illusion of ontological determinacy they experience as 'staying alive'. Barad explores the way in which these entangled dynamics disrupt binaries like human/nonhuman, presence/absence, and life/death, in their discussion of a well-known quantum experiment where physicists measure puzzling 'diffraction patterns' in light.

\section{Diffractive Reading Practice: Affirming Absence with a Speaking Silence}

Barad positions their diffractive methodology as a form of reading practice by examining Niels Bohr's account of the paradoxical behaviour of light. ${ }^{[13]}$ Bohr describes the double-slit experiment, where entities like atoms or photons are sent through two slits and observed on a screen to find out whether they are waves or particles. When this experiment is done with light particles, for example, a diffractive scatter pattern of light and dark stripes appears on the screen, indicating wave interference. When there is wave interference, the waves alternately cancel each other out and create dark spots. However, this wave pattern is not observed if the measurement apparatus changes to detect which slit the entities move through. Moreover, if the detector measurements are erased after the light beam has passed through the apparatus, the diffractive wave pattern somehow returns. This disturbance of the particle/wave binary is a paradoxical phenomenon that contradicts the laws of classical physics regarding space and time, puzzling physicists. Rather than consider whether this observation suggests the past can be erased or changed, however, Barad argues:

The past was never simply there to begin with and the future is not simply what will unfold; the 'past' and the 'future' are iteratively reworked and enfolded through the iterative practices of spacetimemattering - including the which-slit measurement and the subsequent erasure of which-slit information - all are one phenomenon. (Barad, "Quantum Entanglements" 260)

Katniss and Buttercup also play with this light/dark binary during their flashlight game. Katniss observes that when the light is out, "Buttercup's temporarily distraught and confused, but he recovers and moves on to other things" (Collins, Mockingjay 113). This foregrounds a sense of possibility and presence of movement in the darkness. The way in which past and future events collide to construct their present reality during their game allegorically affirms Barad's iterative practice of spacetimemattering:

The two-slit diffraction experiment queers the binary light/darkness story. What the pattern reveals is that darkness is not a lack. Darkness can be produced by 'adding new light' to existing light - 'to that which it has already received'. Darkness is not mere absence, but rather an abundance when the light goes out. (Barad, "Diffracting" 171)

Barad disturbs this presence/absence binary further by discussing erasure in the context of spacetime. Just as the detector measurements are not truly 'erased' in the double-slit experiment, Barad argues that "while it is possible to erase particular marks that seem to suggest that the 'past' has been changed, it is a fantasy to believe that this constitutes an erasure of all traces of this history" ("Troubling Time/s" 73). They elaborate on this with quantum field theory (QFT), stating that anything 'erased' enters a 'void' and not even a void can be determined 
'empty' in quantum mechanics due to the indeterminacy principle (Barad, "Troubling Time/s" 77). Notably, this does not prove anything is present in the void; rather, it blurs the presence/absence binary so that 'absent' no longer denotes finite emptiness or erasure, but possibility and trace. The idea manifests in The Hunger Games when Buttercup disappears and reappears throughout the narrative, presumed dead, then blinks back into existence whenever he encounters Katniss. It is as though Buttercup only 'exists' as Buttercup during these intraactions. And that may be the case, as the flashlight game and two-slit diffraction test both illustrate, because time is not linear and erasure is not possible; reality, like the quantum vacuum, is in a constant and infinite state of possible (re)configurations. Further, where no entity can be determinately erased, it seems that death performs differently; it is possible that death is constructive rather than negating.

Likewise, most of an atom's mass is made up of the energy, or "virtual particles" (Barad, "Troubling Time/s" 77) that configure the indeterminant vacuum: "According to QFT, as a result of time-being indeterminacy, the electron does not exist as an isolated particle but is always already inseparable from the wild activities of the vacuum" (79). We can view Buttercup as this type of time-being; when Katniss finds him for the final time, she feels he has sprung "out of nowhere" and "it takes a while to believe he's real" (Collins, Mockingjay 269). Katniss and Buttercup cross and shift boundaries throughout the series, moving illegally across district borders, finding each other in places neither of them is supposed to be, surviving together in ways that disrupt binary conceptions of reality. Ultimately, as a vast group of embodied entanglements, Katniss-Buttercup configure reality by intra-acting in the same way that all "matter emerges out of and includes as part of its being the ongoing reconfiguring of boundaries ... they are ongoing material [re]configurings of the world" (Barad, "Posthumanist Performativity" 173). The indeterminacy of quantum absence reconfigures erasure as "filled with the indeterminate murmurings of all possible sounds: it is a speaking silence" (Barad, "Troubling Time/s" 77). Katniss embodies a 'speaking silence' in the immediate aftermath of her sister's death. As doctors attempt to erase her wounds from the explosion that killed her sister Primrose, Katniss finds she has become mute: "Dead, but not allowed to die. Alive, but as good as dead . . . my silence has been brought on by emotional trauma" (Collins, Mockingjay 246). In this scene, Katniss herself takes on the role of Schrödinger's cat. She enters a silence that is filled with murmurings: "There's much pain but there's also something like reality" (246). She experiences vague awareness of different body parts, "lungs" and "sheets of skin", as her mind and body repeat memories of animate and inanimate encounters with voices, "the arena", smells, sensations, and "wings" (246). It is as though 'Katniss' is no longer a 'bound' identity but a boundless intra-activity. She flickers in-and-out of the empty void her sister has disappeared into as she seeks to join the dead and die herself: "'Let me die. Let me follow the others,' I beg whatever holds me here. There's no response" (246; original emphasis). The blurry non-presence of alive-Katniss is privileged as Katniss-the-collection-of-atoms has no apparent, determinate agency. Instead, entanglements between the entities that make up alive-Katniss and those that make up medicine and doctors and 'whatever holds her here' intra-actively configure her aliveness by "manipulating her body parts" and "coaxing the cells into thinking they are [her] own" (246). What Katniss articulates, in her ironic awareness of ontological indeterminacy, is also at the core of Schrödinger's thought experiment with its two possible outcomes. One is a reality in which the cat (Katniss) is alive, and another is a reality in which the cat (Katniss) is dead. In either case, reality is entangled with the cat: all possible environmental entities, including Schrödinger, are entangled with dead-cat or alive-cat. If Schrödinger finds the cat alive, this reality is different from the one in which the cat is found dead but, in the latter case, dead-cat still affects reality as part of intra-active phenomena. Traces of dead-cat always remain because Schrödinger and the surrounding environment are still changed, entangled, configured differently because of the cat. Loss, in this sense, is also constructive and shared across all connected entanglements. 
This expanded view of entanglement as 'reality's connectedness' makes it clear that Primrose is also deeply entangled with Katniss-Buttercup in The Hunger Games. Prim finds Buttercup and brings him to Katniss; Prim's cries interfere with Katniss's attempt to drown him in a bucket; Prim is there, too, when Katniss and Buttercup play the torch-light game. During the explosion that kills Prim, Katniss watches her "little sister become a human torch" in a disturbing iteration of the light/dark binary, where "fire burns brighter in the darkness" (Collins, Mockingjay 248) and death is produced in a blaze of light because "darkness can be produced by 'adding new light' to existing light" (Barad, "Diffracting" 171). Throughout the series, Katniss is dubbed "the girl on fire" (Collins, The Hunger Games 140), and in this encounter with her sister, they are both 'the girl on fire'. The reality of her sister's death is a configuration of acts. In the same way that a light particle is both present and absent in its diffractive pattern, and the torchlight game transforms Buttercup-Katniss, Katniss-Prim also transforms; caught in and configuring phenomena that reverberate across the spacetimemattering of all connected entanglements. As they intra-actively blur the life/death binary in this encounter, Katniss lives and Prim dies. Consequently, in the reality that unfolds during the trilogy's final act, Buttercup once again appears before a surprised Katniss, who this time remarks that he is looking for Prim. At first, Katniss is "furious with him" for expecting to find dead-Prim but then, they "both end up crying . . . only this time [they] comfort each other" (Collins, Mockingjay 269). It seems that in this reality, where Prim is dead, Buttercup-Prim's entanglement draws Buttercup to Katniss and it is in this here-now that Katniss and Buttercup can finally find comfort in one another. This final encounter transforms their dynamic and configures their experience of grief, suggesting that dead-Prim's entanglements continue to affect the reality experienced by and through her entanglements and their redistribution. Prim no longer lives but because of Prim's bond with Buttercup, Katniss responds differently to the presumed-dead cat this time around. Katniss reasons: "He must know the unthinkable has happened and to survive must require previously unthinkable acts" (Collins, Mockingjay 270). These 'previously unthinkable acts', such as Buttercup and Katniss comforting one another, are those acts that cannot be configured in any 'other' reality where Prim survives.

\section{Death of the Sister: Constructive Mourning and (Im)probable Narratives}

Entanglement is productive: Prim's non-presence continues to transform reality for all with whom she shares entanglements. Using Barad's terminology, 'Prim' as an indeterminant group of entangled entities repeats differently in a constant renewal of reality wherever her memory is reconfigured. It is as though "the world 'holds' the memory of all traces; or rather, the world is its memory (enfolded materialisation)" (Barad, "Quantum Entanglements" 261). Characters plant primrose flowers in the scorched earth of her home district; Katniss and others vote on whether to bring back the Hunger Games event "for Prim" (Collins, Mockingjay 259); Katniss ends a cycle of televised violence by killing the rebellion leader in her sister's memory; the physical, social, psychological environment is transformed along with 'Katniss', who proclaims "I transform" (261). Barad argues that:

Mourning is not about making memorials, but rather about ontologically reconfiguring a past that never was on behalf of possibilities for a better future, not as performed by a willful liberal humanist subject, but in the tracings of entanglements of multiple time-beings. ("Troubling Time/s" 86)

Katniss mourns Prim by helping to reconfigure their dystopian reality, in which children are routinely starved and murdered, into a utopian reality filled with primrose flowers. Katniss finds that "it benefits no-one to live in a world where these things happen" (Collins, Mockingjay 264). So, in dead-Prim's reality, Katniss-Prim and other entangled characters configure a past that never was, in which dead-Prim could have remained alive, on behalf of 
possibilities for a better future. As Barad argues: "There can never be complete redemption, but spacetimematter can be productively reconfigured, as im/possibilities are reworked" (“Quantum Entanglements" 266). The reconfiguration of spacetimematter into a utopian reality inspired by dead-Prim has just as much 'Prim' in it as the dystopian reality home to alive-Prim. This is because singular entities are only 'as much' as their innumerable, indeterminate entangled traces, which transform but remain. As in a diffractive reading, the blurriness of binaries like presence/absence and life/death make dying different because it is no longer a definitive absence. Another example of this is Katniss's dead father's joke, which takes on further renewed meaning: "As long as you can find yourself, you'll never starve" (Collins, The Hunger Games 49). As an embodiment of her entanglement with Prim, Katniss (as Katniss-Prim) co-creates a primrose flower-filled reality where the Hunger Games no longer exists, and she will never starve. Mourning becomes a performative life-death superposition.

This is a good time to revisit Schrödinger's thought experiment because it was never really about a cat, and neither is The Hunger Games. Schrödinger posited his thought experiment to highlight the absurdity of a mathematically sound equation. The Schrödinger equation calculates the probability that an atom will decay in a given timeframe, but it cannot predict a certain outcome. It cannot actually determine whether or not the atom will decay. Barad notes: "The Schrödinger equation leaves us with the superposition and doesn't account for its resolution into one definite state or another (that is, dead or alive) upon measurement" ("Living" 169). Probability and uncertainty are central to quantum mechanics and Barad's account of material reality. They are also essential to The Hunger Games. "May the odds be ever in your favour" is the token line delivered to children while they wait to find out whether they have been randomly selected to compete in a televised fight to the death (Collins, Hunger Games 18). The Hunger Games event is an annual reconfiguration of a rebellion fought more than seven decades previous, to show "how little chance [citizens] would stand of surviving another rebellion" (17). As child tributes train to compete, wealthy citizens place bets on who is most likely to die, how, and when; "sponsors" can also pay to send food and medicine into the arena, attempting to stack the odds (248). The novels toy with the idea of probability; while Schrödinger specifies a $50 \%$ chance of death for his cat to illustrate the fundamental indeterminacy of the cat's alive-dead state, The Hunger Games illustrates that even with stacked odds, there's still indeterminacy. Primrose is selected as a tribute even though her name is only entered once among "thousands of slips” (19). The narrative clarifies: “The odds had been entirely in her favor. But it hadn't mattered” (20). When Katniss volunteers in Prim's place, Katniss laments that she has a low chance of winning the Hunger Games because she is malnourished and from a poor district. Yet, she survives. All these (im)probable acts signal indeterminacy.

Masked in probability, perhaps the trilogy's titular fight-to-the-death competition operates as a giant double-slit experiment: the entities perceived as 'Katniss' and the other 'tributes' are made up of 'particles' that are all ultimately in superposition. Barad comments that in quantum physics: "To be in a state of superposition between two positions . . . is not to be here or there, or even simply here and there: rather, it is to be indeterminately herethere - that is, there is no fact of the matter (it is not simply that it is unknown) as to whether it is here or there" ("Troubling Time/s" 65). It is possible for the gamemakers to measure Katniss's position in the arena at any point in time and to predict where and when she has the highest probability of death, by factoring environmental possibilities within the arena such as physical characteristics and number of sponsors, just as "quantum probabilities are calculated by taking account of all possible paths connecting the two points" (Barad, "Troubling Time/s" 66). However, this does not mean the gamemakers can actually determine any specific, fixed outcome for 'Katniss'. Just like particles measured at particular points of spacetime during the double-slit experiment are actually wavelengths in many places at once, creating a diffractive pattern; 'Katniss' is not actually a fixed point in 
spacetime or a smattering of particles captured on camera, but an entangled wavelength. Katniss exists across spacetimematter in people's memories and conversations, in plant-form feeding her family as katniss, on digital screens stoking rebellion in the districts; she is entangled with her sister Prim, the elusive and boundless Buttercup, and other tributes she encounters and mutually transforms. If the tributes entering the arena are like light particles sent through two slits, the Hunger Games phenomena is an intra-active wavelength formed by tribute and environmental intra-activity. In other words, "they all coexist and mutually contribute to the overall pattern" and every (im)probable outcome is indeterminate because "the total probability is a superposition or a sum of all possible paths" (Barad, "Troubling Time/s" 66). The Hunger Games and Schrödinger's thought experiment thus offer similar rhetoric: they both superficially insinuate that mathematically (im)probable outcomes can accurately predict certain points in spacetimematter but they both underscore the absurd fact that all probability results in superposition and measurement is always bound by some level of uncertainty. While it is possible to try to predict and to measure finite states of life/death, quantum principles of uncertainty and indeterminacy dictate that these predictions are based on probability and measurements do not actually affirm the existence of any finite life/death binary.

\section{Temporal Diffraction and the Memory of Dying}

Where Schrödinger's equation calculates the probability that an atom will decay in a given timeframe, time is also indeterminate. Barad explains how "temporal diffraction is the manifestation of an ontological indeterminacy of time: there is no fact of the matter to when it is taking place" ("Troubling Time/s" 68). The first novel introduces the Hunger Games competition as a "yearly reminder that the Dark Days must never be repeated" (Collins, The Hunger Games 17): it is a brutal, televised, mandatory act of remembrance in which 24 children from 12 districts "fight to the death" until one child is left alive to be paraded as a "victor" synonymous with the luxury of the rebellion's victorious Capitol city $(17,18)$. The competition is reconfigured every year to keep the historic war present in the minds of citizens. So, while the competition seems to exist in 'the present' at a regulated point in spacetime, it is phenomena configured by past war and future rebellion. Disturbing the concept of linear time, the Hunger Games is "indeterminately coexisting at multiple times" (Barad, "Troubling Time/s" 66). The marks of the event remain visible on victors' bodies through injuries, developing addictions, and ongoing abuses; citizens relive the violence in nightmares and on televised highlight reels that interrupt their working lives; accounts of the Hunger Games are woven into school curricula and re-enacted on playgrounds. As Barad articulates: "The sedimenting material effects of these very reconfigurings -memories/re-member-ings - are written into the flesh of the world (Barad, "Quantum Entanglements" 266). As intra-activity, the Hunger Games constantly transforms individual lives, shapes families, and even reconfigures landscapes when arenas are built and destroyed as reiterations of every past and future arena. The Hunger Games phenomenon is, essentially, mourning. Where Katniss and her entanglements reconfigure new realities in the wake of 'Prim's' blurry death, the Hunger Games is another form of mourning that is "not about making memorials, but rather about ontologically reconfiguring a past that never was" (Barad, "Troubling Time/s" 86). It repeats war differently, diffractively, to create a version of a previous rebellion "on behalf of possibilities for a better future" that avoids another rebellion (86).

The second novel further explores temporal diffraction by disturbing the concept of linear time through Katniss and Prim's entanglement. In Catching Fire, the arena is designed like a clock: the landscape is sliced into 12 segments, each segment posing a new threat for tributes to overcome. Each torment lasts one hour and alternates in clockwise rotation to mimic linear time-keeping. When Katniss realises she is located within a "clockwork" arena, the arena spins and reconfigures itself to 'erase' what she just observed (Collins, Catching Fire 
232). The tributes scramble to figure out which segment is safe, which time is 'the present', and which location is the 'here-now'. However, it becomes clear that not only do they no longer know when-where they are positioned but that "temporal diffraction is the manifestation of an ontological indeterminacy of time: there is no fact of the matter to when it is taking place" (Barad, "Troubling Time/s" 68). The tributes begin to question reality: they "randomly choose a path" (Collins, Catching Fire 236) and Katniss is swarmed by birds that shriek in her sister's "agonized" and "irretrievable" voice (239). Prim does not die until the third novel in the linear storyline but Katniss emphatically insists: "She's probably dead" (241) and grieves the loss of her sister. The future/past binary blurs when the indeterminacy of spacetime manifests. Prim is ontologically alive-dead in this scene because of her entanglement with Katniss, who cannot know for sure whether her sister is alive, and this temporal superposition produces a pattern of mourning that the novels continue to highlight. When, in Mockingjay, Katniss encounters Prim's 'real-time' death, she visualises her sister as a "small white bird" and hears her screaming as though she is remembering her sister die in the non-clock arena rather than watching her die in the 'real world' (Collins 245). 'Real-time' does not make sense without linear temporality, so Katniss questions whether this death is "real" (245). It echoes Derrida's inference that humans textually construct cats in so far as they perceive them despite believing that cats exist outside text, as other. 'Katniss' configures her sister's death in so far as she experiences it. For Katniss, Prim dies but she was always-already alive-dead and will continue to be present-absent. In the context of entanglement, Prim does not die in the here-now at the end of the trilogy but in a non-linear (re)configuration of spacetimematter. The Katniss-Prim relation is one of constructive mourning.

In the first novel, Katniss's fears about the probability of her sister's death compel her to volunteer as tribute and transform into a rebel leader; in the third novel, Katniss's memories of Prim compel her to bond with Buttercup and participate in the renewal of her district. The Katniss-Prim-Buttercup relation, like "the diffraction pattern ... is a manifestation of different times bleeding through one another" (Barad, "Troubling Time/s" 68). Is it possible that all entanglements, all encounters, produce mourning as well as superposition? If Schrödinger's equation predicts the probability of atom decay in a given timeframe and always results in a superposition of alive-dead, and if mourning also blurs the life-death binary as a spacetimemattering reconfiguration of a supposed past and possible futures, then perhaps mourning is best understood as a superposition. Here, life may be understood as intra-active phenomena, ${ }^{[14]}$ always resulting in a superposition of mourning, rather than a temporal location ahead of death's endpoint. Ultimately, reading Karen Barad's account of Erwin Schrödinger's Cat Paradox through Suzanne Collins' The Hunger Games series interrogates ontology and probability to underscore the impossibility of a finite life/death binary.

Moreover, by developing its diffractive methodology, this reading explores the literary applications of Barad's work on quantum ontology. These applications articulate literary diffraction as a mode of reading practice with several important contributions. Centrally, it considers reading as a process of reconfiguring knowledge by iteratively (re)working texts through one another in affirming ways. This approach differs from traditional literary criticism by seeking to produce new perspectives and concepts by reworking rather than negating existing ones. By way of example, reading The Hunger Games through Barad's interpretation of Schrödinger's Cat Paradox privileges the entangled Katniss-Prim-Buttercup relation over normative identity categories like 'sister' and 'pet' without negating these categories altogether. It follows that the concept of constructive mourning may articulate the experience of 'being' a relation, of encountering another, whether that encounter is human-animal, sister-sister, or otherwise. In this framework, 'identity' or 'self' operate as entangled configurations of (im)probable duration, only traceable by "being bound to the other", rather than simply as finite singularities (Barad, "Quantum Entanglements" 265). Following this logic, reading Jacques Derrida's cat encounter through Barad's work on 
intra-action also positions text and human perception as part of entangled phenomena, positioning diffractive reading practice 'itself' as constructive rather than critical. In other words, diffractive methodologies reconfigure reading practice as intra-activity that is also part of the continual reconfiguring of material reality that Barad discusses. Literary diffraction contributes a mode of reading practice that challenges the reader to read different texts and knowledges together in ways that produce possibilities for unexpected configurations of meaning. Ultimately, where entangled relations continually reconfigure, mourning cannot signify finite loss but renewal; just as the particles that make up spacetimematter are an indeterminately infinite wavelength encompassing all that ever was and whatever may become. 'Buttercup' can therefore be read as the indeterminately alive-dead result of Schrödinger's thought experiment and the entangled time-being with whom Katniss mourns her sister. Erasure gives way to reconfiguration and possibility; death affirms the productive redistribution of entanglements; and Buttercup, an unlikely example, embodies the intra-activity of mourning that is perhaps central to posthuman, entangled (non)identity.

\section{Works Cited}

Barad, Karen. “Diffracting Diffraction: Cutting Together-Apart.” Parallax, vol. 20, no. 3, 2014, pp. 168-87.

---. "Hauntological Relations of Inheritance: dis/Continuities, Spacetime Enfoldings, and Justice-to-Come." Derrida Today, vol. 3, no. 2, 2010, pp. 240-68.

---. "Invertebrate Visions: Diffractions of the Brittlestar." The Multispecies Salon, edited by Eben Kirksey, Duke UP, 2014, pp. 221-41.

---. "Living in a Posthumanist Material World: Lessons from Schrödinger's Cat." Bits of Life, edited by Anneke Smelik and Nina Lykke, University of Washington Press, 2008, pp. 165-76.

---. Meeting the Universe Halfway Quantum Physics and the Entanglement of Matter and Meaning. Duke UP, 2007.

---. “Nature’s Queer Performativity.” Qui Parle, vol. 19 no. 2, 2011, pp. 121-58.

---. "Posthumanist Performativity: Toward an Understanding of How Matter Comes to Matter." Signs, vol. 28 , no. 3, 2003, pp. 801-31.

---. "Quantum Entanglements and Hauntological Relations of Inheritance: Dis/continuities, SpaceTime Enfoldings, and Justice-to-Come." Derrida Today, vol. 3, no. 2, 2010, pp. 240-68.

---. "Troubling Time/s and Ecologies of Nothingness: Re-Turning, Re-Membering, and Facing the Incalculable." New Formations, no. 92, 2017, pp. 56-86. ProQuest, doi:10.3898/NEWF:92.05.2017.

---. "What is the Measure of Nothingness? Infinity, Virtuality, Justice." 100 Notes, 100 Thoughts: Documenta Series 099, Hatje Cantz, 2012. 
---. "What Flashes Up: Theological-Political-Scientific Fragments." Entangled Worlds: Religion, Science, and New Materialisms, edited by Catherine Keller, Mary-Jane Rubenstein. Fordham UP, 2017, pp. 21-88.

Briggs, Robert. "Following the Animal-to-Come." Derrida Today, vol. 12, no. 1, 2019, pp. 20-40.

Collins, Suzanne. The Hunger Games. Scholastic Press, 2008.

---. Catching Fire. Scholastic Press, 2013.

---. Mockingjay. Scholastic Press, 2014.

Crockett, Clayton. "Quantum Derrida Barad's Hauntological Materialism." Derrida After the End of Writing. Fordham UP, 2017, pp. 121-38.

Derrida, Jacques. Specters of Marx: The State of the Debt, the Work of Mourning, \& the New International. Translated by Peggy Kamuf, Routledge, 1994.

---. The Animal That Therefore I Am. Translated by David Wills, Fordham UP, 2008.

Edmond, Jacob. "Diffracted Waves and World Literature." Parallax, no. 3, 2014, pp. 245-57.

Fling, Holly. "Fanny Price's Curation of Lively Things in Mansfield Park." European Romantic Review, vol. 31, no. 4, 2020, pp. 401-20.

Gadenne, Donelle and Annie Potts. "Felines on the Fault Line: Cats and the Christchurch Earthquakes." Animal Places: Lively Cartographies of Human-Animal Relations, edited by Jacob Bull, Tora Holmberg, Cecilia Åsberg. Routledge, 2017, pp. 51-66.

Gough, Noel and Chessa Adsit-Morris. "Troubling the Anthropocene: Donna Haraway, Science Fiction, and Arts of Un/Naming." Cultural Studies Cultural Methodologies, vol. 20, no. 3, 2020, pp. 213-24.

Haraway, Donna. "Conversations with Donna Haraway." Interview by Joseph Schneider. Donna Haraway: Live Theory, Continuum, 2005, pp. 114-56.

---. "Encounters with Companion Species: Entangling Dogs, Baboons, Philosophers, and Biologists." Configurations, vol. 14, no. 1, 2006, pp. 97-114. ProQuest, https://search-proquestcom.ezproxy.library.uq.edu.au/docview/217808271?accountid=14723.

---. The Companion Species Manifesto: Dogs, People, and Significant Otherness. Prickly Paradigm Press, 2003.

Lönngren, Ann-Sofie. "Following the Animal: Place, Space and Literature." Animal Places: Lively Cartographies of Human-Animal Relations, edited by Jacob Bull, Tora Holmberg, Cecilia Åsberg. Routledge, 2017, pp. $231-47$. 
Marovich, Beatrice. "The Trouble with Commonality: Theology, Evolutionary Theory, and Creaturely Kinship." Entangled Worlds: Religion, Science, and New Materialisms, edited by Catherine Keller, Mary-Jane Rubenstein. Fordham UP, 2017, pp. 317-30.

Neyrat, Frédéric. Literature and Materialisms. Routledge, 2020.

Penn, Alexandra. "Perception of the Object": Toward a Material-Discursive Poetics. 2019. Indiana University, Phd Thesis. ProQuest, www.search-proquest-com.ezproxy.library.uq.edu.au/docview/2313733114?accountid=14723.

Rowe, Terra. "Grace in Intra-action: Complementarity and the Noncircular Gift." Entangled Worlds: Religion, Science, and New Materialisms, edited by Catherine Keller, Mary-Jane Rubenstein. Fordham UP, 2017, pp. 27498.

Schrödinger, Erwin. "The Present Situation in Quantum Mechanics: A Translation of Schrödinger's 'Cat Paradox' Paper." Quantum Theory and Measurement, edited by John Archibald Wheeler and Wojciech Hubert Zurek. Translated by John Trimmer, Princeton UP, 1983, pp. 152-67.

Sehgal, Melanie. "Diffractive Propositions: Reading Alfred North Whitehead with Donna Haraway and Karen Barad." Parallax, no. 3, 2014, pp. 188-01.

Sellberg, Karin. 'The 'Turns' of Feminist Time: Evolutionary Logic, Life and Renewal in 'New Materialist' Feminist Philosophy." Australian Feminist Studies, vol. 34, no.99, 2019, pp. 93-06.

Sellberg, Karin, and Peta Hinton. "Introduction: The Possibilities of Feminist Quantum Thinking." Rhizomes, no. 30, 2016. doi:10.20415/rhiz/030.i01.

Schaefer, Donovan O. "Heavenbeast: A New Materialist Approach to Ulysses." Angelaki Journal of the Theoretical Humanities, vol. 21, no. 2, 2016, pp. 119-37.

Van der Tuin, Iris. "A Different Starting Point, A Different Metaphysics: Reading Bergson and Barad Diffractively." Hypatia, vol. 26, no. 1, 2011, pp. 22-42.

\section{Acknowledgements}

Dedicated to Jess, who loved The Hunger Games and hated physics.

Sincere thank you to Dr Karin Sellberg for her guidance and encouragement throughout.

\section{Notes}

1. See Fling's analysis of Mansfield Park for an example of how literary critics may use Baradian theory in more traditional readings. To my knowledge, there are few close literary readings that significantly engage with the work of Karen Barad. 
2. For an experimental diffractive reading inspired by Haraway's account, see Gough and Adsit-Morris.

3. See van der Tuin, also Sehgal, for discussion about how Barad's interpretation of quantum mechanics ontologically extends the diffractive reading strategy originally conceptualised by Haraway.

4. For an exploration of how quantum theories may inform literary theory, see Neyrat.

5. Such as she explores in The Companion Species Manifesto.

6. See Lönngren for how Alice in Wonderland's contextual ties to Charles Darwin's theory of evolution may inform Derrida's thinking on 'the animal' in Western philosophy.

7. For diverse examples of diffractive reading methodologies from scholars across different disciplines, see the 2016 Rhizomes special issue titled, "Quantum Possibilities: The Work of Karen Barad". For examples featuring close textual analysis of poetry, see Edmond and also Penn.

8. See Schaefer's approach to Ulysses for focus on the relationship between Derrida's later work and new materialist interpretations of animalism.

9. Barad considers the 'indebtedness' of entangled relations in their essay, "Hauntological Relations of Inheritance: dis/Continuities, Spacetime Enfoldings, and Justice-to-Come", which draws from another Derrida work, Specters of Marx: The State of the Debt, the Work of Mourning, \& the New International.

10. Other critics discuss the human-animal relation following Derrida and Barad's work. For example, see Marovich's discussion of "creaturely kinship".

11. There is some work in the realm of animality on the logic of 'following'; see Briggs' article "Following the animal-to-come" for discussion around Derrida's attempt to 'follow the animal' through philosophy.

12. In their study of human-feline relationships post-Christchurch earthquake, Gadenne and Potts make a relevant observation that "for many people, despite having endured the chaos of losing communities, houses, and neighbours, it was the return of a beloved cat that finally enabled some emotional release" (63).

13. See Rowe on Bohr's account of wave-particle duality in relation to Derrida's theory of supplementarity.

14. Barad's framework is part of the new materialist 'turn' in feminist philosophy that configures life in ways which trouble time and blur binary logic surrounding the material/conceptual. For insight on divergent theories around 'newness' and 'renewal' that are foundational to new materialist philosophies of life and temporality, see Sellberg.

\section{Cite this Essay}

Clarke, Rosie. "Schrödinger's Katniss: A Diffractive Reading of Quantum Entanglement and The Hunger Games." Rhizomes: Cultural Studies in Emerging Knowledge, no. 37, 2021, doi:10.20415/rhiz/037.e01

RHIZOMES ISSN 1555-9998 $\star 230$ East Hall Bowling Green State University Bowling Green, OH 43403

Editors: Ellen Berry and Carol Siegel. Reviews editor: Craig J. Saper. Technical editor: Helen J Burgess 